\title{
Junturas teóricas para los feminismos del Sur'
}

\section{Theoretical junctures for the Southern feminisms Junções teóricas para os feminismos do Sul}

\author{
Dra. Mariana Alvarado²
}

Recibido: 30 de mayo de 2018 . Aceptado: 20 de agosto de 2018

\begin{abstract}
Resumen:
El escrito invita a transitar las formas en las que el feminismo ha sido historiado, para detenerse en las aportaciones dispersas y discontinuas del feminismo latinoamericano como teoría política y filosofía práctica. Situadas las mujeres en el sur, es posible advertir los recorridos díscolos del movimiento de mujeres/feministas en Latinoamérica, en ese borde impreciso que presenta la juntura academia/activismo, institucionales/ autónomas, técnicas del género/militantes, lugares de indagación en los que mujeres desobedientes han gestado epistemologías alteradoras. ¿Cuáles han sido los desplazamientos caminados por las teóricas feministas de Nuestra América? ¿Cómo se traman esos re-comienzos? ¿Han sido las mismas nuestras precariedades, nuestras afecciones condicionantes? ¿De qué luchas hemos sido eco? ¿Cómo acoplan modernidad/ilustración/ emancipación en nuestras coordenadas? ¿Subalternas y marginadas en las mismas opresiones? ¿Qué mujeres en cuáles territorios? Lo que sigue en este artículo es apenas un mapa para reconocer -al modo de un estado de situación- las trazas en el territorio y disponer de una red
\end{abstract}

1 Este texto se escribe al tiempo que tienen lugar las audiencias informativas y las jornadas de debate en el Congreso de la República Argentina sobre el proyecto de ley de interrupción voluntaria del embarazo (IVE), presentado por la Campaña Nacional por el Derecho al Aborto Legal, Seguro y Gratuito. En Mendoza, junto a Claudia Anzorena, coordinamos Seminario de lectura y comentario de textos: experiencias y narrativas contemporáneas de los feminismos del Sur. Debates políticos actuales, un espacio de indagación colectiva destinado a la formación de los miembros del PICT 2016-0590 que dirijo; las primeras articulaciones de pensares, quehaceres y decires de una comunidad epistémica en contexto.

2 Argentina. Doctora en Filosofía (FFyL - UNCuyo, Mendoza, Argentina). Investigadora Adjunta (INCIHUSA - CCT - Mendoza - CONICET Argentina) Contacto: unodeloscuartos@gmail.com

ORCID: https://orcid.org/0000-0001-5562-1697 
de sentidos y categorías que configuren el campo de la teoría para los feminismos del sur.

Palabras claves: Genealogías - zona de contacto - comunidad - experiencias corporizadas

\begin{abstract}
:
This paper invites to go through the ways in which feminism has been historized, to observe the dispersed and discontinuous contributions of Latin American feminism as political theory and practical philosophy. With women located in the South, it is possible to see the unruly paths of women/feminist movement in Latin America, in that vague edge presented by the relations between academic/activism, institutional/autonomous, gender/militant techniques, places of inquiry in which Disobedient women have developed altering epistemologies. What have been the paths made by the feminist theorists of Our America? How are these new beginnings plotted? Our precariousness, our conditions have been the same? What struggles have we echoed? How do modernity/illustration/ emancipation couple in our coordinates? Subaltern and marginalized in the same oppressions? What women in which territories? What follows in this article is just a map to recognize traces in the territory -as a state of affairs- and to have a network of meanings and categories configuring the theory field for Southern feminisms.
\end{abstract}

Keywords: Genealogies - contact area - community - embodied experiences

\title{
Resumo:
}

O escrito convida a transitar as formas nas que o feminismo tem sido historiado, para deter-se nas contribuições dispersas e descontínuas do feminismo latino-americano como teoria política e filosofia prática. Situadas as mulheres no sul, é possível advertir os percursos díscolos do movimento de mulheres/feministas na América Latina, nessa margem imprecisa que apresenta a junção academia/ativismo, institucionais/ autônomas, técnicas do gênero/militantes, lugares de indagação no que mulheres desobedientes têm gestado epistemologias alteradoras. Quais têm sido os deslocamentos caminhados pelas teóricas feministas de Nossa América? Como se tramam esses recomeços? Têm sido as mesmas nossas precariedades, nossas afeições condicionantes? De que lutas temos sido eco? Como acoplam modernidade/ilustração/emancipação em nossas coordenadas? Subalternas e marginadas nas mesmas opressões? Que mulheres em quais territórios? O que se segue neste artigo é apenas um mapa para reconhecer -ao modo de um estado de situação-as linhas no território e dispor de uma rede de sentidos e categorias que configurem o campo da teoria para os feminismos do sul.

Palavras-chave: Genealogias - zona de contato - comunidade - experiências corporizadas 


\section{Feminismos euro-norte-centrados}

La historia de las mujeres ha dado cuenta del lugar que han tenido éstas en revueltas y movimientos sociales. Distinguir los movimientos en los que han participado mujeres de los movimientos feministas, permite visibilizar las primeras luchas feministas que, en tensión con el surgimiento de la teoría feminista, trazan una doble huella para el feminismo: como movimiento social y tradición teórica (De Miguel y Cobo 1997 203).

Para pensar las condiciones de acción y las formas de articulación entre teoría y política en el campo del feminismo "es preciso tener en cuenta que entre la historia del feminismo en los países centrales y la del feminismo en la periferia latinoamericana hay tiempos y ritmos desiguales" (Ciriza 2007 28). Ligadas al cuestionamiento de las relaciones asimétricas de poder entre los sexos, aparecen diversos posicionamientos teóricos (liberales, radicales, materialistas, autónomas, institucionales, activistas, académicas) que contextualizan la opresión, dependencia y subalternidad de las mujeres atentas a sus consecuencias políticas. El uso del singular resulta paradójico e incluso contradictorio; diverso, plural, múltiple y complejo, devino, en su doble traza, muchos feminismos.

Como tradición teórica, el feminismo se articula en la modernidad ${ }^{3}$ enlazado al proyecto ilustrado (Amorós 2000). Si bien el Contrato Social funciona como modelo para la Revolución, el feminismo es la primera interrupción al democratismo ilustrado; como discurso de

\footnotetext{
3 Tentativas feministas previas las hubo: como la formulada en la querella de las damas en la Europa medieval; una de las mujeres visibilizadas en ese periodo fue Christine de Pizan (1364-1430), también podría encontrarse en lo que Amelia Valcárcel (2001) ha denominado "discurso de la excelencia de las nobles mujeres" (santas o heroínas, damas o reinas); en Nuestra América, en la voz de la mexicana Juana Inés de la Cruz (1651-1695), también pueden rastrearse en algunas narradoras como la brasileña Teresa Margarita da Silva e Orta (1711-1793) o en militantes socialistas como la peruana Flora Tristán (1803-1844). Cartas, novelas, ensayos, poemas, manifiestos y proclamas son intentos en los que pueden anclarse diversas posiciones que más tarde se traducen en las primeras luchas feministas, cuando el feminismo devino colectivo.
} 
vindicación ${ }^{4}$, fundado en la igualdad ${ }^{5}$, cobra hondura como pensamiento filosófico político y social en las voces de la filósofa política francesa Olympe de Gouges, con su "Declaración de los derechos de las mujeres y la ciudadana" (1791), y de la inglesa Mary Wollstonecraft en la "Vindicación de los derechos de la mujer" (1792). En el marco de la filosofía política moderna -lo que conocemos como teoría contractualista del Estado y en las figuras de Locke, Hobbes y Rousseau como derecho natural racional-, el feminismo es el primer discurso correctivo a la democracia liberal, resultado de la polémica sobre la libertad, la igualdad y la diferencia entre los sexos. A propósito de $E I$ Contrato Social y el Emilio, un nuevo paradigma sociopolítico estaba en ciernes para argumentar contra sus insuficiencias: un contrato sostenido en la voluntad general que no coincidía con la de todos; el sexo excluye parte de la humanidad de la razón y de la voluntad general, niega la ciudadanía a las mujeres y escinde lo público de lo privado; el origen de la exclusión en la naturaleza determina el modelo de mujer que sacraliza y la esfera política que le corresponde, desde la educación de Sofía a La Nueva Eloísa, como destino impuesto en la mujer-esposa/mujer-madre ${ }^{6}$.

El feminismo ilustrado desfonda la ancestral jerarquía entre los sexos y de estirpe; lo que los varones ejercen sobre las mujeres no es autoridad

4 Celia Amorós (2000) propone una periodización similar a la tradicional, aunque sitúa a la primera Ola en el cartesianismo, a la segunda en el sufragismo, con quien lleva hasta sus últimas consecuencias teóricas las concepciones de igualdad, Simone de Beauvoir y, luego, el feminismo de los 70. Amelia Valcárcel (2001) ubica al feminismo ilustrado en la primera Ola, al liberal en la segunda y al sesentaochentista en la tercera.

5 La concepción ilustrada de igualdad de la Revolución Francesa (1789) no se extendía al género humano: se restringía a varones libres, ciudadanos, adultos; a la igualdad estamental entre nobles, clérigos y villanos; se expresaba en abstracciones universalizadoras -individuo, sujeto, ciudadano-, íconos horizontales (Valcárcel 2014). El feminismo ilustrado liberal radicaliza el proyecto ilustrado vindicando el lugar de las mujeres -fuera del orden doméstico como madres y esposas- como ciudadanas, es decir, como sujetos políticos, como sujetos de derecho.

6 En esa trama, la cuestión de la ciudadanía se liga por un lado con la tradición que deviene de la revolución de la independencia norteamericana de 1776 y, por otro, la tradición política vinculada a la Revolución Francesa en su versión republicana y democrática bajo la consigna jacobina. 
natural sino privilegio; la situación de las mujeres no tiene otro origen que la doble dominación -sexo/clase-; arremeter contra la opresión de una no puede desentenderse de la otra. El primer feminismo pudo formular teóricamente en clave política sus demandas: deconstruir el concepto de ciudadanía y el modelo de feminidad?.

La lucha por la ciudadanía y el sufragio adquieren modulaciones teóricas en la búsqueda por el lugar de "la mujer" en el espacio público. La teoría feminista devela la estructura de subordinación de la mujer en el sistema de dominación entre los sexos: el patriarcado. El análisis crítico de los mecanismos de dominio patriarcal adquiere diversas marcas como feminismo liberal de tradición ilustrada: el socialista, el feminismo radical, el cultural, feminismo de la indiferencia, feminismo posmoderno.

En el siglo XIX el feminismo adviene como movimiento social internacional emancipatorio. En tiempos en los que las relaciones entre los sexos se alteraron notablemente, el derecho a voto y a la educación se configuraban como reconocimiento interclasista. Mientras la mujer obrera se incorporaba al trabajo industrial como mano de obra -más barata y dócil-, las mujeres de la burguesía adinerada como clase social ascendente permanecían en sus hogares como símbolo de éxito laboral del varón.

Por un lado, la misoginia romántica (Valcárcel 2001 32-34) acuñada por la tradición filosófica occidental, en las voces de Friedrich Hegel, Arthur Schopenhauer, Soren Kierkegaard y Friedrich Nietzsche ${ }^{8}$,

7 La educación y la jurisprudencia eran los pendientes para salir del tutelaje del padre, del esposo e incluso del hijo. La obediencia, el respeto, la subordinación, el sacrificio, la abnegación, la sumisión eran -valores impuestos como virtudes femeninas- los modos que reglaban los vínculos para las mujeres. El derecho penal fijó delitos con nombre de mujer: aborto, abandono, adulterio, infanticidio. Ninguna dueña de sí, alejada de voluntad propia, el cuerpo y la sexualidad fueron el lugar del tutelaje. Sin capacidad ciudadana, alejadas de todo saber y excluidas de los tramos medios y superiores de la educación, obtener los bienes y derechos liberales fueron las luchas del sufragismo. 8 La filosofía que releva a la religión pudo intervenir en la formación de campos de conocimiento científico, técnico y humanista, en la producción discursiva histórica, literaria, sociológica e incluso en las artes plásticas. En la actualidad, las ideas de las 
sostenía la ficción de "la mujer" ideal, sin principio de individuación; insistiendo en la naturalización del fin que le era "propio" -procreación para la maternidad, sexualidad para la reproducción-, desde una política de esencialización del género femenino contra la vindicación de igualdad entre sexos bajo la pretendida complementariedad, deja a las mujeres sin derechos reales ni libertades ciudadanas.

Por otro lado, la incorporación del socialismo y el marxismo al movimiento obrero propiciaba elementos para pensar las relaciones sociales en clave dominado-dominador. En 1848, Karl Marx y Friedrich Engels publican, en Londres, el Manifiesto Comunista y, en Séneca Falls, se aprueba la Declaración de Sentimientos. El modelo de la declaración fue el de Declaración de la Independencia de Estados Unidos. Varones y mujeres venidos de círculos abolicionistas -en los que las mujeres activistas eran mayoría- encontraron paralelismos entre el tráfico, la tenencia y venta de esclavos y la servidumbre femenina. Lucretia Mott y Elizabeth Cady comandaron la declaración de Séneca con la que tiene su texto fundacional el feminismo sufragista que, en cuanto movimiento internacional tuvo lugar en todas las sociedades industriales.

cabezas que teorizaron por qué las mujeres debían estar excluidas son material de estudio en diversas carreras universitarias en Argentina. En el caso del profesorado y de la licenciatura en filosofía, en Mendoza, el iusnaturalismo, el contractualismo, el racionalismo y el idealismo son construcciones teóricas vertebradoras de los programas de varias materias. Si bien se sabe de intenciones, desconozco que alguna de las cátedras haga espacio a intervenciones en perspectiva de género o interrupciones desde la teoría feminista (Cfr. Alvarado 2017 33-47).

9 Los requerimientos para el derecho al sufragio -de los varones- se sostenían en argumentos misóginos: los poseedores de una determinada renta, pero no las escasas poseedoras de la misma situación; los que podían asegurar(se) subsistir pero no para las empleadas; el varón podía votar por su condición de tal pero ninguna mujer podía hacerlo sin importar cuál fuera la suya. Algunos de los aportes del movimiento sufragista, del que la política democrática es deudora, están vinculados a la sustitución de "fraternidad" (frater: hermano varón) por "solidaridad", desde donde propuso modos de intervención y de lucha política pacíficos: huelga de hambre, autoencadenamiento, tirada de panfletos, manifestaciones, interrupción de oradores con preguntas (Cfr. Valcárcel 201 56). 
Friedrich Engels quita el fundamento biológico naturalizado a la subordinación para situarlo en la propiedad privada; si bien incitaba la entrada de las mujeres a la producción asalariada y pregonaba el acceso a la independencia económica, el marxismo insistía en las diferencias de clase que separaban a las mujeres, invisibilizando la dominación patriarcal; la subordinación de las mujeres tenía/tiene características específicas que no son implicadas por la explotación de los trabajadores sino, en todo caso, se articulaban de manera simultánea y fundante. El patriarcado precede al capitalismo, aunque capitalismo implica patriarcado. El feminismo socialista apunta los nombres de la editora alemana del periódico de mujeres socialistas Die Gleichheit Clara Zetkin (1857-1933) y, luego, los de las pensadoras contemporáneas anglosajonas de Iris Marion Young (1949-2006), Zillah Eisenstein (1948), Heidi Hartman (1945), pero también los aportes desde la teoría crítica de Nancy Fraser (1947) y Seyla Benhabib (1950).

En Europa Harriet Taylor (1807-1858) combate el naturalismo con La emancipación de la mujer y, con su segundo esposo, John Stuart Mill (1806-1873), el autor de La sujeción de la mujer (1869) -quien presenta y defiende la petición en favor del voto femenino, firmada por más de mil mujeres, en la Cámara de los Comunes, el Parlamento, hacia 1866- presenta las bases teóricas desde las que el sufragismo pudiera pensar una ciudadanía no excluyente, sustituyendo la voluntad general por el interés común.

Durante los ochenta años -casi tres generaciones- que demoró el reconocimiento de los derechos liberales -educación y voto-, los varones fueron a la guerra y las mujeres a las fábricas, quedando en evidencia que las mujeres podían lo que la misoginia les arrebataba.

Con Simone de Beauvoir y El segundo sexo $(1949)^{10}$ se desplaza la "cuestión femenina" hacia la pareja, la familia y la sexualidad, al colocar a "la mujer" como categoría de análisis. Las mujeres son las otras en

10 Celia Amorós sugiere que los aportes de Simone de Beauvoir articulan la segunda -las sufragistas- y la tercera olas, etapas que inaugura y de la que se convierte en ícono (feminismo de los 60). 
relación con el hombre, pero él nunca es otro para las mujeres; por el contrario, él es la medida de todas (las) nuestras cosas. El sujeto (el ciudadano, el hombre, el ser humano) es siempre masculino, el otro, por el contrario, se verifica desde el varón en cada momento como heterodesignación. Somos dichas. Los varones impiden que las mujeres se asuman en su devenir, terminamos por identificarnos en/con el proyecto que ellos hacen de nosotras. La feminidad es construida, no se nace con ella, devenimos las que somos.

El feminismo de los 60 emerge de la coyuntura: la lucha armada, la resistencia de Vietnam contra la herencia colonialista francesa recogida por EEUU, la New Left, el beatnik, la píldora, el movimiento pro-derechos civiles de las personas de color en USA, el movimiento hippie, el movimiento estudiantil y el mayo del 68. Los nuevos movimientos se planteaban cuáles debían ser sus formas organizativas, así como sus vínculos con las instituciones políticas convencionales. Develar el papel asignado a las mujeres en los partidos de izquierda $y$ en el resto de los movimientos sociales, puertas adentro y afuera de las instituciones, confirmó que las mujeres ocupaban los mismos lugares asignados al rol.

Betty Friedan habla de un malestar innominado, el "problema que no tiene nombre", en La mística de la feminidad (1963), texto que abre a los feminismos de los 60. Las mujeres del norte experimentaron una profunda insatisfacción al saberse definidas como directoras del hogar, amas de casa, esposas, madres, fregonas y servidoras de las necesidades físicas de sus maridos y prole. La alianza entre los gobiernos y los medios masivos de comunicación, con su aparato de gráfica y propaganda, puso en movimiento campañas que pretendían alejar a las mujeres de sus nuevos trabajos, devolverlas al hogar, diversificar la producción fabril y replicar a "la mujer" ahora como "la nueva mujer". Para lograrlo, las mujeres debían entender cuál era su lugar y qué es lo que se esperaba de ellas; el espacio abandonado provisoriamente sería ocupado con el estereotipo reforzado con los primeros electrodomésticos que salen a la venta -cocinas, lavarropas, heladeras, secadoras, batidoras- y que prometían modernos medios para agilizar las tareas domésticas y para contar con más 
tiempo para seguir tomadas por tareas para otros ${ }^{11}$; con derechos ciudadanos reconocidos recientemente, con educación elemental o media, debían (re)conocer(se) en el rol de ama de casa libre -de elegir permanecer en el hogar-y competente -no solo administraba la economía del hogar sino también las relaciones por las que el marido podía progresar y mostrar su progreso: reuniones, asociaciones, alianzas, cenas, partys-. La mística visibiliza los modos en los que la familia nuclear deja de ser una unidad productiva para convertirse en unidad de consumo, al tiempo que la escisión público/privado cobra hondura ya no en su naturalización, sino en el imperativo de la complementariedad, la heterosexualidad como política de mercado y la heteronormatividad ${ }^{12}$.

Años más tarde, en The Second Stage (1981), describía la doble explotación a la que estamos sujetas en tanto los varones no quieran compartir-tareas de crianza, cuidado y limpieza- la inmanencia de la vida, la repetición frente a la trascendencia. Los fundamentos teóricos del marxismo, el psicoanálisis y el anticolonialismo se articulan en el feminismo radical de Kate Millet y su Política Sexual (1970) y Sulamith Firestone (1945-2012) en su La dialéctica del sexo (1970).

Entre los 70 y los 80 los nombres de Andrea Dworkin -feminista radical- (1979-2005), Catharine MacKinnon (1946), Nancy Chodorow (1944) y Carol Gilligan (1936) articulan discursos con aportes de la teoría psicoanalítica contra la pornografía, en lo que ha sido conocido como "feminismo cultural". Luce Irigaray (1930) y Carla Lonzi (19311982) despliegan en Europa un feminismo de la diferencia.

\footnotetext{
11 Marcas aún conocidas por nosotras, prometía lavarropas que "lava de una vez la colada de una familia de seis personas", para que la mujer pueda disponer su tiempo para cocinar. Mientras la lavadora lava para nosotras, nosotras cocinamos para todos. Recuperado de https://www.pinterest.es/pin/715579828267032960/

12 Contradicción al margen la de apelar a la ficción de "la mujer" para obtener formación/educación/instrucción para cumplir con las funciones asignadas al rol (esposa/ madre). Los conocimientos de lectura y escritura, incluso los de cálculo, parecían pertinentes para la (su)misión requerida por el orden doméstico. Los reclamos de acceso e ingreso a los tramos medios del sistema se ampararon en la maternidad y el matrimonio como destino impuesto.
} 
En los años de posguerra, el ideal por el reconocimiento entre mujeres animó los encuentros entre ellas en grupos de autoconciencia -bautizados así por Carla Lonzi-, en los que entraban en diálogo, habilitando y legitimando la voz de cada una. Estos pequeños grupos llevaron la vida privada a la política y pusieron en debate la politicidad de la vida privada, emprendieron acciones e intervenciones en la esfera pública, en medios de comunicación y universidades, para identificar, denunciar y transformar el sexismo (Gargallo 2004 8). Lo que aparece por primera vez en la revista de los grupos feministas de Milán, Sottosopra (1983), en el artículo "Más mujeres que hombres", como affidamento ${ }^{13}$, refería al reconocimiento entre mujeres y para mujeres a través de la autoestima; una práctica feminista que supuso la disparidad entre mujeres, reconocía saberes disímiles, potenciaba generosamente las diferencias legitimando los decires de unas para hacer frente a las necesidades y urgencias de otras (Ciriza 2008 27; Rodríguez Agüero 2013 91). Un modo otro de hacer política, de encontrarse en el relato sobre nuestro estar en el mundo, en el deseo y en el dolor de la otra; de traducir la anécdota a categoría; de generar conocimiento desde las experiencias de las mujeres, que pudo corporizarse en organizaciones y asociaciones y, luego, en redes desde las que pudieron sostenerse autónomamente respecto de los partidos políticos, los gobiernos y organismos internacionales; la autonomía política ha sido coincidencia en las diversas formas del movimiento feminista: liberal, socialista, radical, de la diferencia y académicas.

El feminismo cultural trazó lazos con el lesbianismo, atento a que la práctica de la heterosexualidad sería una forma no deseable de alianza con el enemigo. El feminismo posmoderno puso coto a los grandes relatos de la modernidad en sus ideales emancipatorios y priorizó la

\footnotetext{
13 Affidamento: no habría traducción literal. Vinculado a affidabilitá- difucia- reputazione -custoida- difucia, refiere de algún modo a "aquellas con las que has contado"; "las que te han hospedado"; "quienes te contienen"; "en quienes te sostienes"; "confiar"; "dejarse sostener"; "apoyarse"; "dejarse aconsejar". Postula relaciones de intercambio entre mujeres, quienes se comprometen a prestar ayuda para realizar proyectos o deseos. Construir un espacio de seguridad para habilitar el diálogo entre nosotras, (re)estableciendo lazos de confianza.
} 
deconstrucción de nociones generalizadores, tales como la de "mujer" como sujeto único.

Advertida ya la trampa patriarcal contra la vida de las mujeres en el privilegio jurídico-político del que gozaban los espacios de la política y el mercado, en los noventa la discriminación positiva posibilitó la promoción de medidas para asegurar la presencia y visibilidad de mujeres en todos los tramos; el sistema de cuotas y la paridad fueron los instrumentos para ponerle coto a la dinámica de las exclusiones y asegurar la llegada de "minorías" a lugares impensados. La conversión de algunas feministas en expertas del género pudo analogarse a la gestación de políticas públicas como acciones divorciadas de la política de mujeres.

\section{Feminismo filosófico latinoamericano}

En el siglo XX, la difusión de los ideales de igualdad entre mujeres y hombres y la creciente conciencia de exclusión sistemática de los aportes de las mujeres al saber colectivo -y de la visibilidad de su condición y necesidades- dio origen al conjunto de teorías feministas que confluyen en el feminismo filosófico de América Latina y el Caribe (Gargallo $2011420)$.

Preguntar por la presencia de las mujeres en la filosofía occidental; rescatar lo dicho sobre las mujeres desde la filosofía euronortecentrada o bien indagar en algunos usos que algunas filósofas hacen de otros para hacer su propia filosofía, son algunos de los caminos que podemos andar para vérnosla con la cuestión de las mujeres aquí, en la periferia latinoamericana. En las dos primeras formas reforzaríamos el centro desde donde nosotras somos las otras, siguiendo la huella de las ausentes, olvidadas, evitadas, silenciadas, o bien gestando una re-lectura del canon filosófico, en lo que hemos apuntado como la "misoginia del romanticismo" -siguiendo las líneas de Femenías-, desde donde sería posible intervenir, interrumpir y re-configurar una historia de la filosofía (occidental, moderna y contemporánea) desde las voces de las mujeres, y parirnos un archivo otro filosófico, femi- 
nista y desde América Latina (Cfr. Alvarado 2017); tal vez una cuarta ruta desfonde lo que habitualmente entendemos por "filosofía", para referir a la sujeto que piensa y hace filosofía situada y en contexto como feminismo filosófico o filosofía feminista ${ }^{14}$. Algunas preguntas iniciales acusan incomodidades: si el feminismo es internacional o internacionalista, ¿qué implicancias tiene hablar de un feminismo latinoamericano?; la sucesión de las olas, tradicionalmente usada por el feminismo occidental euronortecentrado para sistematizar la historia de los feminismos, ¿da cuenta de la realidad regional? ¿Cuáles fueron las especificidades del feminismo para declararse italiano o español cuando tuvieron que vérselas con el catolicismo, el fascismo y la represión? ¿De dónde proceden nuestros feminismos y cómo es que les cabe lo latinoamericano? ¿Cuáles son las experiencias que marcan la historia del movimiento aquí, en el sur? ¿Podemos advertir los episodios que lo configuran en Nuestra América? ¿Cómo entendemos nosotras nuestros propios recorridos? ¿Quiénes nosotras? ¿Las proletarias? ¿Las trabajadoras de la ciencia? ¿Las campesinas explotadas? ¿Las obreras del pensamiento? ¿Las mujeres racializadas? ¿Las trabajadoras sexuales? ¿Las sindicalistas? ¿Autónomas? ¿Activistas? ¿Militantes? ¿Académicas? Dispersas, (des)conocidas para otras, (in) esperadas para algunas.

El feminismo filosófico latinoamericano ha sido marginado de la reproducción de conocimiento en la academia, no solo por feminista sino también por latinoamericano. El pensamiento latinoamericano ha sido vinculado a la sociología, a la teoría política, al historicismo. En la década del setenta la historia de las ideas, la teoría de la dependencia y la filosofía de la liberación articularon conquista, colonización, modernidad y capital para diagnosticar el lugar de América Latina en la circulación centro/periferia y el extractivismo Norte/Sur. Los pensares, experiencias y quehaceres de mujeres delimitan territorios situados y críticos como teoría feminista, feminismo filosófico, feminismos, mo-

\footnotetext{
14 Toca detenernos en cuál sea la conjunción entre filosofía, feminismos, movimiento de mujeres y estudios de género aquí en América Latina. No da lo mismo y no es lo mismo aquí en el sur.
} 
vimientos de mujeres, feminismos del sur; epistemologías feministas como políticas del lugar de enunciación que instalan preguntas que aquellos filósofos latinoamericanos no tuvieron en cuenta. Sin embargo, nuestros feminismos comparten con el pensamiento latinoamericano, en todo caso, la exploración y mixtura de diversas tradiciones, no solo las euronortecentradas sino, sobre todo, un "desde dónde" produce discurso: práctica política. La producción discursiva de los feminismos latinoamericanos ha tenido lugar en un contexto determinado por la conquista, la esclavitud africana, las migraciones europeas y la minorización de las poblaciones indígenas. A estas posibilidades de vérnoslas con el feminismo filosófico de/en América Latina se suman al menos tres obstáculos epistemológicos.

El trazado de una geografía de la difusión de ideas feministas en la Argentina de los tempranos '70, supone asumir -como dato no menor-la diversidad, no sistematicidad y pluralidad de caminos y perspectivas que dieron lugar a la formación de distintos núcleos de recepción en los cuales estas ideas fueron resignificadas, contaminándose con otras posiciones y perspectivas y produciendo efectos de los más diversos (Rodríguez Agüero 2013 90).

Tras los pasos discontinuos, lazos fragmentados nos anudan. Dispersas, sin reconocer especificidades procedentes en nuestra región, asistimos al borramiento de ideas ancestrales y saberes autóctonos situados en las experiencias de las mujeres de Nuestra América. Cabe al menos señalar-apoyados(as) en la historia de las ideas- que estos pensares tienen una historia -fragmentaria, episódica, discontinua (Cfr. Roig 2008 131-140; Arpini 2017 11-15)-, cuya emergencia responde a claves epistémico-políticas. Escapar a la pretensión de continuidad depende de un volver a pensar al sujeto descorporizado del filosofar -en algún punto situado por el pensamiento latinoamericano, en las versiones aludidas líneas arriba-, ahora corporizado en la historicidad de los pensares, experiencias y quehaceres de mujeres -desde la teoría feminista-; pensar otra sujeto implica el corrimiento de las formas en las que han sido formuladas ciertas preguntas y explicadas académicamente -un corrimiento que desfonda la metodología, 
los materiales, los géneros, los criterios de periodización, los bordes disciplinares-. Los sentidos cobran hondura en estas tierras ${ }^{15}$ en las articulaciones de voces, en un trazado de genealogías que se traman al deseo por afirmar(se) en la discontinuidad de una historia no enseñada, no aprendida, no sabida todavía, por accesoria e irrelevante para el conocimiento logofalocentrado.

Nuestras genealogías ${ }^{16}$ tienen múltiples y contradictorias raíces,

a menudo dobles y contenciosas, tensadas por asuntos como el de las lenguas, la ubicación, la racialización de la población nativa y de las personas afro, la clase social, los procesos de occidentalización de nuestra cultura, las selecciones narrativas operadas sobre nuestra historia, las dificultades para disponer de documentos pues no se preserva lo que se considera irrelevante (Ciriza 2015 84).

Nuestras genealogías están por ser anudadas. Optar por trazar relaciones con quienes nos precedieron en la crítica a la dominación patriarcal es un gesto político que requiere de una pesquisa particular. El tono

15 Denominadas por los europeos "América" que devino luego "Latina". Para considerar la cuestión del nombre puede verse América Latina, la construcción del orden (Ansaldi y Giordano 2012 59-64). Para diversas comunidades indígenas Abya Yala. Para ampliar la violencia sin equívocos que se operó de la conquista al colonialismo, puede verse Ansaldi y Giordano (2012 69-85). Mención especial merecen algunas de las descalificaciones propiciadas por la eurocéntrica invención/construcción de América en el registro de Hegel, Marx y Louis Leclerc.

16 Genealogía/s comparte la misma raíz latina que género del latín genus-eris: linaje, rama, pueblo, raza, descendiente, clase, generación, género, especie, casta. Término que incluye en su raíz latina raza/clase/género. En inglés se ha usado gender o genre, que para las lenguas neolatinas implica una taxonomía entre dos sexos. Ha sido un concepto productivo con el que fue posible revelar las desigualdades entre varones y mujeres. En el apellido del padre somos incorporadas a un orden de generaciones patrilineales que no nos permite nombrar las diversas formas en las que nos vinculamos las mujeres. Gayle Rubin visibiliza el sistema sexo/género como la combinación monótona y aparentemente variada de subordinación y explotación del sexo femenino que justifica la apropiación de su sexualidad por el parentesco. Sin embargo, en tanto ha sido encadenado a la diferencia sexual biológica, se trata de una categoría limitada para pensar las posibilidades que habitan el entre y desbordan el binarismo heteronormado. 
con el que Gilda Luongo da cuenta de su propio posicionamiento crítico feminista, perseguido en una primera aproximación a la poesía de mujeres mapuche, nos acerca al movimiento de aquel gesto.

Llegar a la poesía de mujeres mapuche como quien entra a un territorio que pide una pisada tenue, de pie pelado. No porque haya que tener cuidado, ni porque incite un despliegue epistémico heteróclito. Esta demanda de lo delicado, de lo delgado o débil en el paso indagativo tiene que ver -desde esta sujeto y su lenguaje crítico- con el territorio denso-pleno en diferencias diferentes marcadas a fuego por la historia, la sociedad chilena y la cultura mestiza (Luongo 2012).

Un gesto parido de la necesidad y la urgencia de hallar raíces para nuestras interrupciones teóricas y políticas al monólogo falogocentrado y la violencia machista, pero también a las formas en las que el feminismo ha sido dicho. Darnos la voz entre nosotras, sin ser habladas por otros, procura de un horizonte de comprensión en un campo de sentido sostenido por una zona de contacto: un trazado de continuidades en las interrupciones. ¿De qué interrupciones hablamos? ¿Cuándo y cómo hemos interrumpido? ¿Cuáles han sido las particulares formas en las que nos han acallado, oprimido, explotado, exterminado aquí, en el sur? ¿De qué modo estas preguntas suponen indagaciones distintas y solapan materiales? ¿Cómo podemos acceder a esos recomienzos? ¿Cuáles son las posibilidades de articulación que se aperturan desde el sur, entre quiénes y hacia qué nortes?

Escribir y pensar la experiencia de mujeres desde su emergencia en América Latina implica para la mexicana Eli Barta Muria (1947) por lo menos cuatro re-comienzos: el feminismo anterior a los 70; el neofeminismo surgido en los setenta; los inicios del XXI; el feminismo actual. Virginia Vargas (1945) entiende que el feminismo se desarrolla en Latinoamérica hacia la década de los 70, para generalizarse en la década de los 80 en tres vertientes: la feminista propiamente dicha, la de mujeres urbano-populares, la vinculada al sindicato o partidos políticos. Una identidad feminista que, si bien se despliega con fuerza inicial en Brasil, México, Perú, Colombia, Argentina, Chile, Uruguay, 
el Caribe de habla hispana y Cuba, se articula entre las profesionales en temas de mujeres y las militantes de un movimiento en formación.

María Luisa Femenías (1950) sugiere un re-comienzo para las ideas feministas en Argentina, en el feminismo ilustrado del XVIII de raigambre liberal; otro en el XIX, en un feminismo clasista que vincula socialistas y anarquistas, $\mathrm{y}$ un tercero con el retorno de la democracia en los 80 en la figura de "las Madres" como pioneras de la lucha por la memoria, la verdad y la justicia (Cfr. Calvera 1990).

Las ahora mundialmente conocidas Madres de Plaza de Mayo, de Argentina, y sus similares contrapartes menos conocidas de Chile, Uruguay, Nicaragua y Honduras, se convirtieron en íconos de la movilización en nombre de la maternidad, activando poder político a partir del ubicuo espacio doméstico. Dieron a la maternidad y a la familia la fuerza política que era el sueño de las feministas latinoamericanas a principios del siglo XX. La denuncia de las torturas $y$ asesinatos por parte de mujeres claramente "apolítica" tenía un contenido ético profundo y ganó un considerable respeto, precisamente porque el arquetipo de la entrega maternal estaba por encima de las consideraciones políticas y tenía raíces culturales profundas (Lavrin 2001 213-214).

En los trazos de estos mapas es posible marcar algunas huellas que podrían fragmentar el camino en derroteros de incipientes feminismos a fines del siglo XIX. El Censo de 1869 daba cuenta de que la mitad de la población de mujeres argentinas trabajaba: costureras, lavanderas, planchadoras, panaderas, cigarreras; hacia 1888 se registra la primera huelga de domésticas -por la imposición de la libreta de conchabo- a las que seguirán las costureras, fosforeras y lavanderas, dando lugar a una intensa actividad huelguista; las trabajadoras telefónicas y empleadas de comercio empiezan a organizarse en sindicatos; entre 1869 y 1914 la inmigración implica décadas de reacomodamiento de clases y lucha con/por/contra el capital, y propicia la apropiación del trabajo y del cuerpo de las mujeres: el mercado de prostitutas y la trata. El mercado ya tenía color y clase. 
Prueba de ello son las organizaciones, acciones y textos escritos por mujeres de la época: Petrona Eyle (1866-1945) junto a Cecilia Grierson (1859-1934) - primera médica graduada en Argentina- fundan la Asociación de Universitarias Argentinas y, junto a otras, sostuvieron durante algunos años la Liga contra la trata de blancas. En esta trama, Juana Manso (1819-1975), Juana Manuela Gorriti (1818-1892), Florencia Fossatti (1888-1978) y Angélica Mendoza (1889-1960) intervienen en educación y el magisterio desde un anclaje feminista (Cfr. Alvarado 2016 y 2017; Ferreira de Cassone 2017). En La Vanguardia, Fenia Chertkoff (1869-1927), en su columna "El trabajo de las mujeres y de los niños", lo visibiliza y denuncia. Decires, sentires y pensares encorsetados en cartas, confesiones, diarios íntimos, ensayos, lecciones, conferencias pedagógicas, actas, poemas, novelas, no constituyen un corpus sino itinerarios por donde ir configurando una trama colectiva. Desde 1906, en que comenzó a publicarse La Voz de la Mujer, hasta la aparición de Vida Femenina - Revista de la mujer inteligente, dirigida por María L. Berrondo, folletos, hojas sueltas, artículos en diarios, revistas y periódicos, fueron marcando hitos de la intensa actividad de las mujeres. En La Aljaba -primer periódico feminista-, cuya aparición data de 1830, al que le sucede veinte años después La Camelia, en La Flor del Aire, en La Educación - La Siempreviva, también en Nosotras, La Nueva Mujer, Visión y Labor, Tribuna Feminista -dirigida en 1917 por Carolina Muzzili-, o en Nuestra causa -a cargo desde 1919 de la doctora Alicia Moreau de Justo-, los testimonios escritos reflejan los estadios de las bregas feministas en Argentina (Cfr. Rey 2011).

En los derroteros de estos incipientes feminismos inscribo la pregunta por la adscripción de estas mujeres al feminismo: ¿es feminista quien declara serlo o aquella cuyas prácticas abren a la invención de una sujeto que determinada interpretación puede reconocer como feminista? En septiembre de 1947 se sanciona la Ley 13.010, que daba a las mujeres argentinas derechos políticos equiparables a los de los varones. Dos años antes, la Asamblea Nacional de Mujeres - presidida por Victoria Ocampo (1890-1979)- rechaza el voto porque había sido otorgado por "el decreto de un gobierno de facto". Las sufragistas burguesas para Eva Perón (1919-1952)- le dicen no al voto venido de 
un gobierno dictatorial17; sin embargo, sancionada la Ley, las mujeres aceptaron el sufragio y accedieron a las urnas (Calvera 1990 26-29; Vela 2017). Las huellas para situar a la filosofía feminista en nuestras coordenadas vienen dadas finalizando la dictadura hacia 1980 a partir de las voces de tres filósofas extranjeras.

Francesca Gargallo (2009 60-64) sitúa en la década del 80 un comienzo para la filosofía feminista en el sur; la filosofía feminista latinoamericana comienza a desarrollarse en la Argentina con la argentina exiliada María Cristina Lugones (1951), la española Celia Amorós (1944) y la mexicana Graciela Hierro (1978-2993). Con la llegada de Lugones ${ }^{18}$ -feminista anarquista lesbiana militante- a Buenos Aires se configura una zona de contacto a través de un Seminario -del que surge la Asociación Argentina de Mujeres en Filosofía- que pudo corporizarse en una -entre otras- comunidad epistémica de indagación de la que fueron parte Ana María Bach junto a Alicia Gianella, Clara Kuschnir, Diana Maffía, Margarita Roulet y María Isabel Santa Cruz -fundadoras de Hiparquia (1988/1999)-, pioneras como Urania Ungo Montenegro lo fue en Panamá o Julieta Kirkwood y Margarita Pisano en Chile.

Las contingencias económico-políticas del continente marcan las condiciones históricas de producción de ideas y la capacidad de in-

\footnotetext{
17 El derecho al voto fue la meta para las "Damas Patricias", así como para el "Comité Argentino Pro-voto de la Mujer", convertido luego en la "Asociación Argentina del Sufragio Femenino". También lo fue para la "Asociación Pro Sufragio Femenino", la "Asamblea Nacional de Mujeres", la "Federación de Mujeres Universitarias" y la "Liga de Educación Política de la Casa del Pueblo". En estos grupos se abre el debate respecto de la posibilidad de rechazarlo si no era otorgado por el Congreso Nacional. La sede de la Revista Surfue el lugar en el que este debate se sostuvo y Victoria, en La Vanguardia, hacia 1945, lo titula "La mujer y el voto" (Calvera 1990 24-25).

18 Las dificultades de incorporar las ideas feministas latinoamericanas o la teoría feminista o la filosofía feminista responden a ciertos canones de investigación y de docencia académica, ecos de los últimos treinta años. Durante la dictadura argentina no hubo concursos en las universidades. Entre retiros obligados y profesoras exiliadas se cerraron doctorados en tiempos en los que un doctorado se concebía como la instancia final de un recorrido vital, con la que se cerraba una trayectoria. María Lugones regresa después de veinte años de vida en EE.UU., cuando la pretensión era subsanar el vaciamiento académico impuesto entre 1976 y 1986 . Se concursaba, por entonces, Ética en la UBA.
} 
tervención, el tráfico de pensares norte-sur, la recepción, traducción y la circulación de las teorías para sobrevivir(se) en las feministas de lo posible o institucionalizadas, y las feministas autónomas o utópicas; en las especialistas o las metafóricas.

la institucionalización del movimiento (lo que algunas llaman "postfeminismo") no sólo es fruto de un oportunismo económico (con lo cual coincidimos con las feministas autónomas), sino que engendra el peligro real de la profesionalización de algunas feministas, hecho que las convierte en profesionales del género y de la mediatización de las demandas femeninas. Estas mujeres dejaron de ser feministas para convertirse en "expertas en asuntos públicos de las mujeres", especialistas en diálogo con las organizaciones políticas de cuño masculino nacionales e internacionales (Gargallo 32).

Entre las hijas vergonzantes del feminismo, agentes de la globalización, ansiosas por liderar un proceso de cambio al interior de las leyes, y el feminismo latinoamericano hay un conflicto: cuerpo-mujer-economía, que tuvo la forma de la tecnocracia de género para unas y la fidelidad a las ideas marxistas para las otras ${ }^{19}$.

Revisar las transformaciones, los quiebres y contradicciones del movimiento en la Década de la Mujer (1975 a 1985) implica dar cuenta del proceso de "ongización" del movimiento, que hace espacio hacia 1990 a las institucionalistas y/o ongeistas, y a las independientes o autónomas -cercanas a la militancia fundacional del feminismo-. Esta deriva propiciaría la posibilidad de visibilizar el paso de las políticas de reconocimiento a las políticas de identidad. A lo largo de la década del 90 los feminismos transitan identidades múltiples: negras, lesbianas, indígenas, jóvenes, adultas mayores, comunitaristas (Vargas 1996).

19 Tal vez allí puedan anclarse los inicios de lo que hoy se traduce como cuerpoterritorio en los decires de Lorena Cabnal y Delmy Tania Cruz Hernández, que configuran trayectos del feminismo comunitario. 
Construir genealogías, optar por establecer relaciones, implica articular voces y anudar categorías. En ese caminar se traza una zona teórico-política plagada de rupturas y discontinuidades, que corporiza nombres de mujeres en un cuerpo como colectivo político. "[...] para nosotras la búsqueda de genealogías consiste precisamente en recolectar pacientemente lo disperso, a sabiendas de la provisoriedad de las junturas y de la tensión inherente a la tarea misma de la recolección" (Ciriza 2008 26). Esta opción epistémico-metodológica no puede obviar algunas huellas borradas -la modernidad ilustrada en Nuestra América, los procesos de occidentalización y la dictadura argentina-. Reconstruir genealogías feministas en Nuestra América es una tarea difícil. Han sido las feministas que se autodenominan de Abya Yala quienes han optado por el gesto de traer al presente sus ancestras, pariendo un inicio para la teoría feminista latinoamericana en los saberes indígenas; voces difíciles de recuperar, puesto que pocas mestizas se reconocen y autodesignan en ese linaje, prefiriéndose occidentales a indias, blancas a morenas, genéricamente oprimidas a sujetas activas, rebeldes e insumisas, parte de una (her)manada resistencia; el mayor conflicto en el relato que las/nos cuenta es no haber hecho el duelo, no elaborar las muertes de la población originaria al inicio de la occidentalización de la historia del continente (Cfr. Alvarado 2014).

Nuestra ignorancia lingüística no se relaciona con la formación académica que puede aperturarnos un devenir nómade ${ }^{20}$, sino con desconocer las lenguas de nuestra tierra; poco o nada sabemos de las lenguas amerindias: del mapudungun, quichua, nahuatl o aymara.

\footnotetext{
20 La teórica ítalo-australiana Rosi Braidotti, apoyada en Gilles Deleuze, acuña la noción de "sujetos nómades" para referir a un devenir en tránsito aplicable, en la lectura de Alejandra Ciriza, a mujeres feministas académicas, funcionarias internacionales, especialistas del género que viajan y debaten en foros internacionales, y que atraviesan fronteras en determinadas condiciones privilegiadas por la clase a la que pertenecen; educadas, políglotas en lenguas viperinas del inglés, el alemán o el francés; a distancia de las mujeres migrantes que transitan fronteras en condiciones no elegidas y que hablan lenguas, dialectos para los países de destino, imposibles de ligar para aquellas. La potencia de la noción puede ser aplicada en otro sentido al leído por Ciriza: a sujetos en tránsito e identidades desacomodadas respecto del orden patriarcal, del mercado clasista y racista, de las identidades de género.
} 
¿Bastaría con abrir las puertas de la Universidad? (Cfr. Alvarado 2015). Occidentalizadas para las feministas comunitaristas, poco podemos hacer las académicas más que aprender para empezar a escuchar a las mujeres de los pueblos originarios, las feministas de Abya Yala. (Cfr. Gargallo 2014).

Iniciarnos en el camino de la descolonización de la propia teoría requeriría revisar las encrucijadas de la ilustración para los feminismos del sur.

[...] como si la modernidad fuese unitaria y además atributo exclusivo y absoluto de un Occidente sin fisuras ni diferencias y como si otros mundos no pudiesen asumir su propia modernidad [...] La modernidad fue impulsada en muchos países como parte del colonialismo y el neocolonialismo, con expansiones imperialistas diversas. Ligada a prácticas hegemónicas y a procesos devastadores e injustos, se ha convertido para diversas mentalidades, en atributo de los dominadores (Lagarde 36).

Modernidades las hubo y muchas y diversas fueron las racionalidades oscurecidas por la ilustración; un proceso de más de 500 años, a lo largo de los cuales han tenido lugar simultáneas formas de exterminio, explotación, dominación, subyugación, aculturación y mestizaje. El sistema mundo nace entonces con la conquista. La modernidad ha sido un producto de Europa cuya historia mundial empieza a contarse a partir de 1492. ¿Cómo pensar la ilustración en tierras americanas? ¿Cuál es la exigencia de derivar nuestros feminismos del sur de la ilustración europea? ¿Cómo ponerle palabra a la modernidad en Nuestra América sin saber escuchar a las mujeres que la cuentan? ${ }^{21}$

\section{Bibliografía}

Alvarado, Mariana. "Mujeres de América Latina. Episodios para una historia de las ideas pedagógicas del sur: Clorinda Matto de Turner y Florencia

21 Las mujeres peruanas del otro lado de la historia ya están siendo escuchadas (Guardia 2013). 
Fossatti", en: Arpini, Adriana (Comp.) Fragmentos y episodios. Expresiones del pensamiento crítico de América Latina y el Caribe en el siglo XX. Mendoza: Qellqasqa, 2017. 21-46.

Alvarado, Mariana. "Interrupción en Nuestra América con voz de mujeres" en: Alvarado, M. y A. De Oto (edits.) Metodologías en contexto. Intervenciones en perspectiva feminista/poscolonial/ latinoamericana. Buenos Aires: CLACSO, 2017. 33-48. Recuperado de https://www.clacso.org.ar/libreria-latinoamericana/libro detalle.php?id_libro=1341\&pageNum_rs_libros=0\&totalRows_rs_libros=1280

Alvarado, Mariana. "Cociendo pensares a hurtadillas en América del Sur. Juana Manuela Gorriti y Clorinda Matto de Turner". En: Millcallac, revista digital de Ciencias Sociales. Mendoza: UNCuyo, FCPyS, III/5 (2016): 1-18. Recuperado de http://revistas.uncu.edu.ar/ojs/index.php/millca-digital/ article/view/769/477

Alvarado, Mariana. "El Alegato de Florencia Fossatti: claves para una historia de las ideas pedagógicas desde una epistemología feminista", en Caldo, Paula y Marcela Vignoli Dossier (Parte I): Maestras, prácticas género e historia: hacia una historia de la educación con mujeres en los tiempos de la consolidación de los sistemas educativos. Historia de la Educación. Anuario. Bs. As., 17/2 (2016): 104119. Recuperado de http://ppct.caicyt.gov.ar/index.php/anuario/issue/view/ Anuario\%20Historia\%20de\%20la\%20Educaci\%C3\%B3n\%20-\%20SAHE\%20 -\%20Vol.\%2017\%2C\%20N\%C2\%B0\%202/showToc ISSN en línea 2313-9277

Alvarado, Mariana "La educación superior en clave descolonial", en Algarrobo-MEL.com.ar - Sección: Artículos Revista en línea de la Maestría en Estudios Latinoamericanos FCPyS-UNCuyo, 4/4 (2015). Recuperado de www. algarrobo-MEL.com.ar.

Alvarado, Mariana. "Mujeres de América Latina: des(re)encuentros, tráfico de ideas y traducción". Revista Estudios. Filosofía Práctica e Historia de las Ideas, 16/1 (2014): 13-22. Recuperado de http://www.scielo.org.ar/scielo. php?pid=S1851-94902014000100002\&script=sci_arttext

Amorós, Celia (Edit.). Feminismo y filosofía. Madrid: Editorial Síntesis, 2000.

Arpini, Adriana (Comp.) "Sobre fragmentos y episodios, pensamiento crítico y nuestra América" en: Expresiones del pensamiento crítico en América Latina y el Caribe en el siglo XX. Mendoza: Qellqasqa, 2017. 11-20.

Calvera, Leonor. Mujeres y feminismo en la Argentina. Buenos Aires: Grupo editor latinoamericano, 1990.

Ciriza, Alejandra. "Construir genealogías feministas desde el sur: encrucijadas y tensiones" en: MILLCAYAC - Revista Digital de Ciencias Sociales. Mendoza: Centro de Publicaciones. FCPyS. UNCuyo, II/3 (2015): 83-104. 
Ciriza, Alejandra. "Apuntes para una crítica feminista a los atolladeros del género", en Estudios de filosofía práctica e historia de las ideas [online]. Mendoza: Qellqasqa, 9 (2007): 23-41. Recuperado de http://www.scielo.org.ar/ pdf/efphi/n9/n9a03.pdf

Ciriza, Alejandra (Comp.) Intervenciones sobre ciudadanía de mujeres, política y memoria. Perspectivas subalternas. Buenos Aires: Feminaria editora, 2008.

Ciriza, Alejandra. "Movimientos sociales y ciudadanía: notas sobre la ambivalencia ante el espejo de lo colectivo", en La Aljaba Segunda época, XI (2007): 27-43.

De Miguel, Ana y Rosa Cobo. En: Quesada, Fernando (Edit.) Filosofía política I. Ideas políticas y movimientos sociales. Buenos Aires: Editorial Trota, 1997. 203-215.

De Lauretis, T. Diferencias: etapas de un camino a través del feminismo. (M. Echániz Sans, Trad.) Madrid: Horas y Horas, 2000. Cuadernos inacabados 35.

Gargallo, Francesca. Ideas feministas latinoamericanas. México: Universidad de la Ciudad de México, 2009.

Gargallo, Francesca. Feminismos desde Abya Yala. Ideas y proposiciones de mujeres de 607 pueblos de Nuestra América. México: Editorial Corte y Confección, 2014. Recuperado de http://francescagargallo.wordpress.com/

Gargallo, Francesca. "El feminismo filosófico", en Dussel, Enrique, Eduardo Mendieta y Carmen Bohórquez (Eds.), El pensamiento filosófico latinoamericano, del Caribe y latino (1300-2000). México: Siglo XXI Editores, 2011. 418-433.

Ferreira de Casone, Florencia. "Angélica Mendoza y su trayectoria americana", en: Arpini, Adriana (Comp.), Diversidad e integración en Nuestra América. De la modernización a la liberación (1880-1960). Mendoza: Qellqasqa, 2017. 141-150.

Flores, Valeria. "Entre secretos y silencios. La ignorancia como política de conocimiento y práctica de (hetero)normalización", en Revista trabajo social México: UNAM, 18 (2008).

Guardia, Sara Beatriz. Mujeres peruanas El otro lado de la historia. Lima, 2013. Recuperado de http://www.cemhal.org/mujeresperuanas.html

Lagarde, Marcela. "El derecho humano de las mujeres a una vida libre de violencia" Recuperado de http://catedraunescodh.unam.mx/catedra/CONACYT/16_DiplomadoMujeres/lecturas/modulo2/2_MarcelaLagarde_El_derecho_humano_de_las_mujeres_a_una_vida_libre_de_violencia.pdf

Lavrin, Asunción. "Los Feminismos Internacionales: alternativas latinoamericanas" en: Anuario IEHS, Revista Europea de Estudios Latinoamericanos, 16 (2001). 
Luongo, Gilda. "Desplazamientos: escrituras/diferencia sexual/memoria/ política" Conferencia. Universidad de Chile. Doctorado de Literatura Latinoamericana. Octubre de 2017.

Luongo, Gilda. Desplazamientos: escrituras/diferencia sexual/memoria/política. Conferencia en la Universidad de Concepción, 2013.

Luongo, Gilda. "Memoria y revuelta en poetas mujeres mapuche: intimidad/ lazo social I", en Aisthesis. Chile: Pontificia Universidad Católica, 51 (2012): 185-201. Recuperado de https://scielo.conicyt.cl/pdf/aisthesis/n51/art12. pdf última consulta: 22/5/2018

Mendoza, Breny "Los feminismos y la otra transición a la democracia en América Latina", en: García de León, María Antonia (Comp.). Rebeldes ilustradas. La otra transición. Barcelona: Anthropos, 2009.

Pessah, Mariam. "Desmontando los feminicidios". Muestra fotográfica online: Recuperado de https://www.flickr.com/photos/marianapessah/ sets/72157624740515785 Última visita: 12/04/2018

Rei, Ana Lía. "Palabras y proyectos de mujeres socialistas a través de sus revistas (1900-1956)", en Mora Buenos Aires, 17/1 (2011).

Roig, A. "El método del pensar en nuestra América" en: El pensamiento latinoamericano y su aventura. Buenos Aires: Ediciones El Andariego, 2008. 131-140.

Valcárcel, A. La memoria colectiva y los retos del feminismo. Santiago de Chile: CEPAL, Unidad Mujer y Desarrollo, 2001. Serie mujer y desarrollo. Recuperado el 18 de octubre de 2016, de http://repositorio.cepal.org/bitstream/ handle/11362/5877/S01030209_es.pdf;jsessionid=ED1CD1888D89A86A4 8D84CCFF94B94A3?sequence $=1$

Vargas, Virginia, Saskia Wieringa y Geertje Lycklama (Edits). El triángulo del empoderamiento. Bogotá: Tercer Mundo editores, 1996.

Vela, Liliana "Eva Perón: integración social y política de las mujeres argentinas", en Arpini, Adriana (Comp.), Diversidad e integración en Nuestra América. De la modernización a la liberación (1880-1960). Mendoza: Qellqasqa, 2017. 247-258. 